\title{
El abandono de los animales en tiempos de pandemia: perspectiva constitucional, civil y penal
}

\author{
Alberto Varona Jiménez \\ Magistrado \\ Profesor del área penal de la Escuela Judicial del Consejo General del Poder Judicial, España
}

Cita recomendada. VARONA JIMÉNEZ, A., El abandono de los animales en tiempos de pandemia: perspectiva constitucional, civil y penal, dA. Derecho Animal (Forum of Animal Law Studies) 11/4 (2020). DOI https://doi.org/10.5565/rev/da.513

\section{Resumen}

El Covid-19 ha obligado a adoptar medidas con una incidencia directa en los derechos fundamentales de las personas y que han afectado al bienestar social de los ciudadanos, pero cabría preguntarse por los efectos de esta pandemia en los animales. A pesar de algunas medidas del poder ejecutivo, los animales han sido unos de los grandes olvidados. La descosificación de los animales sigue siendo un objetivo imprescindible en nuestro derecho. Los avances habidos en los últimos años en el campo del derecho penal son una esperanza, pero todavía queda un largo camino por recorrer.

Palabras clave: abandono de los animales; pandemia; Covid-19; descosificación; delitos; maltrato animal.

\section{Abstract - Animal abandonment in times of pandemic: constitutional, civil and criminal perspectives}

Covid-19 has forced the adoption of measures with a direct impact on the fundamental rights of people and that have affected the social welfare of citizens, but it might be worth questioning the effects of this pandemic on animals. Despite certain governmental measures of the Government, animals have been some of the most overlooked. The de-objectification of animals continues to be an essential objective of our law. The progress made in the field of criminal law in recent years is hopeful, but there is still a long way to go.

Keywords: animal abandonment; pandemic; Covid-19; de-objectification; crimes; animal abuse. 


\section{La pandemia y el estado de alarma}

Me van a permitir que comience este artículo recuperando unas palabras del padre del utilitarismo, JEREMY BENTHAM. En su obra llamada "introducción a los principios de la moral y la legislación" (1789), este filósofo y jurista británico realizaba la siguiente reflexión:

[...] llegará el día en que el resto de la creación animal podrá adquirir esos derechos que nunca pudieron ser alejados de ellos más que por la mano de la tiranía [...] un caballo o un perro es, más allá de toda comparación, un animal más racional, así como un animal más comunicativo, que un bebé de un día, una semana o hasta un mes. Pero suponga que fuera al revés, ¿qué avalaría? La pregunta no es, ¿pueden razonar? ni ¿pueden hablar?, sino, ¿pueden sufrir? ¿Por qué se negaría la ley a proteger a cualquier ser sensible? Llegará el día en que la humanidad extenderá su manto sobre todo lo que respire.

Tristemente han pasado más de dos siglos y todavía estamos lejos de esta conquista. ${ }^{2}$. Los últimos y tristes acontecimientos que hemos vivido en el año 2020 no son más que un reflejo de aquello. Los humanos hemos sufrido y mucho, pero los animales también. Efectivamente, el año 2020 no será un año más: en los anales de la historia se recordará como el año en que una grave pandemia puso en jaque a un mundo cada vez más globalizado e interconectado; y en nuestras retinas, la tristeza y desolación por la pérdida de seres queridos, y el miedo ante lo invisible y desconocido. Por si alguien tenía dudas, está claro que los virus, como los delitos o la información, no tienen fronteras. La salud de los ciudadanos, la sanidad, la economía y la administración de justicia se han visto seriamente golpeadas. Y ello es así porque para intentar frenar los efectos del Covid-19, ha sido imprescindible que los gobiernos de todos los países adopten medidas que directa o indirectamente tienen incidencia en los derechos fundamentales y en el bienestar social de las personas.

En el caso de España, el Gobierno hizo uso de una de las tres figuras de emergencia previstas en el artículo 116 de la Constitución Española de 1978, la de menor de intensidad: el estado de alarma ${ }^{3}$. Es conveniente recordar las principales características de esta figura: su declaración es competencia del Consejo de Ministros y no requiere de autorización previa del poder legislativo, sino tan solo una dación de cuenta al Congreso de los Diputados. Tiene una duración inicial de 15 días, aunque es prorrogable, en principio sin limitación, con autorización del Congreso, como así ha sucedido durante prácticamente 3 meses. Durante el estado de alarma no puede ser suspendido ningún derecho, a diferencia de los estados de excepción o sitio, donde existe una previsión constitucional en el artículo 55 de la Constitución de suspensión de derechos tan importantes como el derecho a la libertad, a la inviolabilidad del domicilio y de las comunicaciones, el derecho a elegir libremente su residencia y a libre circulación, el derecho a la libertad de expresión o el derecho a libertad de reunión entre otros. Lo que sí permite la Ley Orgánica 4/1981, de 1 de junio, que desarrolla el estado de alarma por mandato constitucional, es que el poder ejecutivo pueda "limitar la circulación o permanencia de personas o vehículos en hora y lugar determinados, o condicionados al cumplimiento de ciertos requisitos"

Al amparo de esta figura de emergencia, el Gobierno suspendió actividades de toda índole, como las actividades de hostelería y restauración (salvo la entrega a domicilio), la actividad educativa presencial a todos los niveles, los museos y la apertura al público de los locales y establecimientos minoristas, con determinadas excepciones como los clínicas veterinarias o locales destinados a la alimentación de los animales. Al mismo tiempo, acordó la limitación a la libre circulación de las personas, permitiendo a las personas circular por las vías de uso público para la realización de determinadas actividades ${ }^{5}$.

Mucho se ha escrito y hablado sobre esta limitación, sobre todo a medida que las prórrogas del estado

\footnotetext{
${ }^{1}$ Cita obtenida en HENAO, S. Eutanasia en animales de compañía, dilemas, encuentros y desencuentros, en Revista Colombiana de Bioética, vol. 11 n. 3 (2017). Página web: https://doi.org/10.18270/rcb.v11i3.2163 (consultado el 27 de julio de 2020).

${ }^{2}$ En España, solamente en el campo del derecho penal albergamos algún horizonte esperanzador desde el año 2003La reforma del Código Penal operada por la Ley Orgánica 15/2003, de 25 de noviembre dio una cobertura específica a la protección penal de los animales domésticos, al tipificar el delito de maltrato animal. Puede consultarse esta reforma en la web https://www.boe.es/buscar/doc.php?id=BOE-A-2003-21538 (consultado el día 2 de agosto de 2020).

${ }^{3}$ El artículo 116 de la Constitución Española de 1978 dispone que "una ley orgánica regulará los estados de alarma, de excepción y de sitio, y las competencias y limitaciones correspondientes". Puede consultarse la Constitución en la web https://www.boe.es/buscar/act.php?id=BOE-A-1978-31229 (consultado el 2 de agosto de 2020).

4 Artículo 11 a) de la Ley Orgánica 4/1981, de 1 de junio, de los estados de alarma, excepción y sitio. Disponible en https://www.boe.es/buscar/act.php?id=BOE-A-1981-12774 (consultado el 2 de agosto de 2020).

${ }^{5}$ Estas medidas fueron acordadas en el Real Decreto 463/2020, de 14 de marzo, por el que se declara el estado de alarma para la gestión de la situación de crisis sanitaria ocasionada por el COVID-19. Puede examinarse completamente esta norma legal en https://www.boe.es/buscar/act.php?id=BOE-A-2020-3692 (consultado el día 25 de julio de 2020).
} 
de alarma se iban sucediendo en el tiempo: no tanto por la idoneidad o no de las medidas de confinamiento, que han sido acogidas por los ciudadanos con un enorme sentido de la responsabilidad y que ni los más escépticos discuten, sino por la cobertura legal de aquellas. La discusión se ha centrado en si las medidas anteriormente expuestas suponen simplemente una restricción de los derechos fundamentales o verdaderamente se ha producido una suspensión de facto de dichos derechos.

El sector de la doctrina que ha defendido lo segundo ${ }^{6}$, y que podemos considerar mayoritario, sostiene que el ejecutivo parte de una prohibición de circulación para establecer a continuación determinadas excepciones en el artículo 7 del Real Decreto por el que se declara el estado de alarma ${ }^{7}$. Por ello, esto sector ha llegado a hablar de un estado de excepción encubierto.

En el polo opuesto se sitúa DE CARRERAS SERRA ${ }^{8}$, quien defiende que el decreto aprobado por el Gobierno no excluye el ejercicio de los principios de proporcionalidad y ponderación, en la medida que se hace una alusión expresa a situaciones de necesidad y a actividades de análoga naturaleza. Mientras sea ponderable el derecho fundamental no podríamos hablar de suspensión. En definitiva, desde esta perspectiva, no estaríamos ante una prohibición sino una restricción ${ }^{9}$.

La resolución de esta cuestión no es sencilla y tampoco es el objeto de este trabajo. Como escribía hace unos meses un Catedrático de Derecho Constitucional de la Universidad de Barcelona, XAVIER ARBÓS, "la pandemia ha pillado al Derecho desprevenido y hay que admitirlo" ${ }^{10}$. En última instancia, será el Tribunal Constitucional el que se pronuncie sobre la legalidad de las medidas, dado que se ha presentado un recurso de inconstitucionalidad contra el Real Decreto y el recurso ha sido admitido a trámite ${ }^{11}$.

\section{Los animales en el estado de alarma}

Las únicas menciones a los animales en el Real Decreto que declara el estado de alarma se limitan a la previsión de no suspensión de la actividad de apertura al público de los establecimientos comerciales minoristas de alimentos para animales de compañía (artículo 10); y a la necesidad de que las autoridades competentes delegadas adopten las medidas necesarias para garantizar corredores sanitarios para permitir la entrada y salida de ciertos establecimientos, y en particular, fábricas de piensos para alimentación animal y mataderos (artículo 15b).

Existe una realidad innegable, que es que cada vez son más los hogares españoles que tienen un integrante en su familia, que no es humano pero siente y padece como tal. Como bien explica GONZÁLEZ LACABEX en un interesante artículo publicado en la web de la abogacía ${ }^{12}$, a lo largo del articulado se observa una expresión que se repite cual mantra: "para la protección de personas, bienes y lugares". Y nosotros nos preguntamos ¿qué derechos tienen los animales? ¿Acaso no tienen los animales domésticos derecho al desconfinamiento?

\footnotetext{
${ }^{6}$ En este sentido, se han pronunciado los Catedráticos de Derecho Constitucional DÍAZ REVORIO, FLORES JUBERÍAS, RUIZ DE MIGUEL, RUIZ ROBLEDO, VERA SANTOS, tanto en los medios de comunicación como en un dictamen disponible en la página web https://www.20minutos.es/uploads/files/2020/04/29/Asunto\%20Curro\%20Dictamen\%20Firmado\%20.pdf (consultado el 1 de agosto de 2020). También el Catedrático de Derecho Procesal PÉREZ-CRUZ MARTíN se ha mostrado muy crítico con la herramienta jurídica utilizada.

${ }^{7}$ El apartado primero de este precepto dispone que "durante la vigencia del estado de alarma, las personas únicamente podrán circular por las vías o espacios de uso público para la realización de las siguientes actividades, que deberán realizarse individualmente, salvo que se acompañe a personas con discapacidad, menores, mayores, o por otra causa justificada: a) Adquisición de alimentos, productos farmacéuticos y de primera necesidad, así como adquisición de otros productos y prestación de servicios de acuerdo con lo establecido en el artículo 10; b) Asistencia a centros, servicios y establecimientos sanitarios; c) Desplazamiento al lugar de trabajo para efectuar su prestación laboral, profesional o empresarial; d) Retorno al lugar de residencia habitual; e) Asistencia y cuidado a mayores, menores, dependientes, personas con discapacidad o personas especialmente vulnerables; f) Desplazamiento a entidades financieras y de seguros; g) Por causa de fuerza mayor o situación de necesidad; h) Cualquier otra actividad de análoga naturaleza".

${ }^{8}$ Opinión expresada en https://www.universidadviu.es/expertos-constitucionalistas-divididos-en-la-aplicacion-del-estado-de-alarmay-la-limitacion-de/ (consultado el 27 de julio de 2020).

9 También se ha pronunciado a favor el Ministro de Justicia, Excmo. Sr. D. JUAN CARLOS CAMPO MORENO, en una columna de opinión publicada en el digital del periódico El Mundo. Disponible en:

https://www.elmundo.es/opinion/2020/04/07/5e8b8934fc6c83372d8b4676.html.

10 Artículo escrito en El Periódico de fecha 31 de marzo de 2020. Disponible en

https://www.elperiodico.com/es/opinion/20200331/articulo-xavier-arbos-derechos-fundamentales-crisis-sanitaria-7912195

(consultado el 2 de agosto de 2020).

${ }^{11}$ Puede verse la providencia de admisión a trámite en

http://www.tribunalconstitucional.es/NotasDePrensaDocumentos/NP_2020_048/P\%202054-2020.pdf (consultado el día 20 de julio de 2020).

${ }^{12}$ Pasear en tiempos de alarma, en el blog de derecho de los animales en la página web

https://www.abogacia.es/publicaciones/blogs/blog-de-derecho-de-los-animales/pasear-en-tiempos-de-alarma/ (consultado el 25 de julio de 2020).
} 
La vía de salida ha sido el artículo 7 del Real Decreto cuando admite la posibilidad de las personas de realizar actividades de análoga naturaleza. Desde el Presidente del Gobierno hasta distintos cargos institucionales reconocieron la posibilidad de "pasear al perro"13. A pesar del uso poco afortunado del verbo, cuando de lo que se trata es de garantizar que el animal pueda realizar sus necesidades fisiológicas, y de la indefinición de lo que se puede o no se puede hacer (por ejemplo, cuánto tiempo y qué distancia) es de reconocer que estas manifestaciones colocaron a los animales en muchas de las páginas, tweets y webs de los medios de comunicación.

Pero como siempre, existe el lado oculto y el abuso de las circunstancias. No hemos estado exentos de una cierta picaresca, en la que en ocasiones los animales de compañía han sido instrumentalizados por distintos miembros de una familia para poder burlar la orden del ejecutivo. No pocos animales habrán pensado qué ha sucedido para que en lugar de tres veces hayan salido continuamente a la vía pública. Por no decir, que el número de adopciones se ha incrementado durante el estado de alarma ${ }^{14}$.

El 19 de marzo de 2020 el Ministerio de Sanidad emitió una instrucción en la que se permiten los desplazamientos de personas cuya finalidad fuera la alimentación, el rescate y el cuidado veterinario de los animales domésticos que habitan en los espacios públicos urbanos ${ }^{15}$.

Esta situación de cierto abandono institucional no es nueva. A diferencia de otros países europeos, el Código Civil español, de fecha 1889, sigue considerando a los animales como cosas, y más concretamente como bienes muebles ${ }^{16}$, conforme a la aquilatada tradición romana que se incorporó a la mayoría de los códigos civiles europeos. Pero nuestra propia Carta Magna, tampoco contiene ninguna referencia a los animales. Es más, dentro de los principios rectores de la política social económica, el derecho es de los ciudadanos a disfrutar de un medio ambiente para el desarrollo de la persona, así como el deber de conservarlo ${ }^{17}$. En definitiva esta situación de desamparo y abandono explica y justifica el título que encabeza este artículo.

No habrá sido por oportunidades. La disolución del parlamento en el año 2018 por falta de consenso político motivó que una proposición de ley, que consideraba a los animales como seres vivos, no fuese aprobada $^{18}$. Se trataba de una reforma que respondía a la mayor sensibilidad social hacia la protección de los animales y que tenía por objeto asumir los compromisos internacionales adquiridos por España. En este sentido, podemos reseñar el artículo 13 del Tratado de Funcionamiento de la Unión Europea y la ratificación hace dos años por parte de nuestro país del Convenio Europeo sobre protección de animales de compañía de $1987^{19}$.

Aquella reforma consideraba a los animales como seres vivos dotados de sensibilidad ${ }^{20}$. Lo que la Dra. GIMÉNEZ-CANDELA ha denominado la "descosificación de los animales" ${ }^{21}$. Al mismo tiempo establecía normas destinadas especialmente a regular las relaciones jurídicas en las que puedan estar implicados animales. En particular, se otorgaba un régimen protector dentro de las normas que regulan las crisis matrimoniales. La reforma contemplaba el régimen de custodia de los animales domésticos y la necesidad de atender al bienestar animal y al interés de los miembros de familia para atribuir su custodia, con independencia de la titularidad dominical, con un régimen de disfrute para el cónyuge no custodio ${ }^{22}$.

\footnotetext{
${ }^{13}$ Comparecencia del Presidente del Gobierno el 14 de marzo de 2020. Disponible en https://www.youtube.com/watch?v=dSbLh9Fud4 (consultado el 25 de julio de 2020).

${ }^{14}$ En este sentido puede verse la página https://www.abogacia.es/publicaciones/blogs/blog-de-derecho-de-los-animales/adopcionesfraudulentas-durante-el-estado-de-alarma/ (consultado el 25 de julio de 2020).

${ }^{15}$ Se trata de la Instrucción de 19 de marzo de 2020 , del Ministerio de Sanidad, por la que se establecen criterios interpretativos para la atención de animales domésticos en la gestión de la situación de crisis sanitaria ocasionada por el COVID-19. Disponible en https:/www.boe.es/buscar/act.php?id=BOE-A-2020-3954 (consultado el 2 de agosto de 2020).

${ }^{16}$ El artículo 333 del Código Civil dispone que "todas las cosas que son o pueden ser objeto de apropiación se consideran como bienes muebles o inmuebles. Y el artículo 335 del mismo texto legal precisa que Se reputan bienes muebles los susceptibles de apropiación no comprendidos en el capítulo anterior, y en general todos los que se pueden transportar de un punto a otro sin menoscabo de la cosa inmueble a que estuvieren unidos". Disponible en https://www.boe.es/buscar/act.php?id=BOE-A-1889-4763 (consultado el 2 de agosto de 2020).

${ }^{17}$ El artículo 45.1 de la Constitución Española dispone que "todos tienen el derecho a disfrutar de un medio ambiente adecuado para el desarrollo de la persona, así como el deber de conservarlo".

${ }^{18}$ Se trata de la Proposición de Ley de modificación del Código Civil, la Ley Hipotecaria y la Ley de Enjuiciamiento Civil, sobre el régimen jurídico de los animales. Disponible en http://www.congreso.es/public_oficiales/L12/CONG/BOCG/B/BOCG-12-B-1675.PDF (consultado el 27 de julio de 2020).

${ }^{19}$ Disponible en https://www.boe.es/diario_boe/txt.php?id=BOE-A-2017-11637 (consultado el 27 de julio de 2020).

${ }^{20}$ La nueva redacción del artículo 333.1 del Código Civil propuesta en la reforma era la siguiente "los animales son seres vivos dotados de sensibilidad. Solo les será aplicable el régimen jurídico de los bienes en la medida en que sea compatible con su naturaleza y con las disposiciones destinadas a su protección".

${ }^{21}$ GIMÉNEZ-CANDELA, T. dA. Revista de derecho animal. Vol. 8, Núm. 2 (2017).

${ }^{22}$ Se introduce un nuevo artículo 94 bis en el Código Civil: "la autoridad judicial confiará para su cuidado a los animales de compañía
} 
Como consecuencia de la falta de aprobación de esta reforma, en el ámbito del derecho civil común actualmente el régimen jurídico aplicable a los animales sigue siendo el régimen jurídico de los bienes ${ }^{23}$. Como regla general, los animales son apropiables y objeto de comercio entre las personas. La relación de la persona con el animal, ya sea de compañía, doméstico, silvestre o salvaje es de propiedad o, en el caso de las Administraciones, de dominio público. Ahora bien, cualquier facultad sobre el animal amparada por dicha relación de propiedad ha de respetar tal cualidad, de modo que el propietario ha de ejercitar dichas facultades atendiendo al bienestar animal, evitando el maltrato, el abandono y la provocación de una muerte cruel. Todo lo anterior resulta paradójico cuando desde el año 2003 el Código Penal distingue entre daños a los animales domésticos y daños a las cosas.

\section{Protección penal de los animales}

A finales del mes de marzo, varios medios de comunicación se hicieron eco de una nota remitida por el Excmo. Sr. D. ANTONIO VERCHER, Fiscal de Sala de Medio Ambiente, a los fiscales delegados y provinciales. En esta nota solicitaba que estuvieran alerta ante la sospecha de que se estaban produciendo adopciones masivas de perros como excusa para poder salir a pasear durante el estado de alarma, lo que planteaba el temor de que, una vez finalizado el confinamiento por el Covid-19, existiese una cadena de abandonos ${ }^{24}$.

Han pasado pocos meses desde el final del estado de alarma y todavía carecemos de datos estadísticos sobre el volumen de atestados y denuncias presentadas sobre esta materia para poder valorar la situación. En cualquier caso, a la vista de esta situación, es importante tener presente la protección que se otorga por el legislador a los animales en el Código Penal. De ella nos vamos a ocupar en las siguientes líneas.

El Código Penal regula los delitos relativos a la fauna y los animales domésticos en los artículos 333 a 337 bis de su texto. En los artículos 333 a 336 del Código Penal, el legislador establece una serie de figuras delictivas en las que se recurre a la técnica de las leyes penales en blanco y que tienen como bien jurídico común protegido el medio ambiente, aunque referido a un factor biótico del mismo como es la fauna ${ }^{25}$.

Así se castiga con pena de hasta 2 años de prisión la introducción de especies no autóctonas, cuando se infrinja la normativa administrativa y se produzca un perjuicio del equilibrio biológico ${ }^{26}$. Con ello se trata de evitar la desaparición de las especies autóctonas. Respecto a las especies protegidas de fauna silvestre, se establece un delito de peligro abstracto castigado igualmente con penas de hasta 2 años de prisión una serie de actividades como su caza, pesca, adquisición, posesión, destrucción, cuando contravenga la normativa administrativa, con una agravación cuando se trata de especies en peligro de extinción ${ }^{27}$. En este caso se prevé la posibilidad de comisión imprudente. Respecto a las especies no protegidas, se castiga la caza o pesca de una especie que esté prohibida totalmente así como también la caza o pesca incumpliendo el régimen administrativo de aprovechamiento ${ }^{28}$. Y por último, con independencia de la especie afectada, motivado por

a uno o ambos cónyuges, atendiendo al interés de los miembros de la familia y al bienestar del animal, con independencia de la titularidad dominical de este".

${ }^{23}$ En el derecho foral cabe destacar la Ley 5/2006, de 10 de mayo, por la que se aprobaba el Libro V del Código civil catalán, relativo a los derechos reales. En su preámbulo se justifica que "de acuerdo con la tradición jurídica catalana más reciente, establece que los animales no tienen la consideración de cosas y están bajo la protección de las leyes”. Por ello dispone en el art. 511-1.3, relativo a los bienes, que "los animales, que no se consideran cosas, están bajo la protección especial de las leyes. Sólo se les aplican las reglas de los bienes en lo que permite su naturaleza". Incluso, en lo relativo a las restricciones al derecho de propiedad (art. 545-1) señala la protección y defensa de los animales como restricción de interés público al derecho de propiedad.

${ }^{24}$ Por ejemplo, https://www.lavanguardia.com/vida/20200330/48169167711/perros-abandonados-fiscalia-estado-de-alarmacoronavirus.html (consultado el día 14 de septiembre de 2020).

${ }^{25}$ MUÑOZ CONDE (2015, p. 511). Sobre el análisis de estos tipos penales y los problemas derivados de la introducción de normas penales en blanco puede verse también el trabajo de JIMÉNEZ, F. (2010).

${ }^{26}$ Artículo 333 del Código Penal: "El que introdujera o liberara especies de flora o fauna no autóctona, de modo que perjudique el equilibrio biológico, contraviniendo las leyes o disposiciones de carácter general protectoras de las especies de flora o fauna, será castigado con la pena de prisión de cuatro meses a dos años o multa de ocho a veinticuatro meses y, en todo caso, inhabilitación especial para profesión u oficio por tiempo de uno a tres años".

27 Artículo 334 del Código Penal: “1. Será castigado con la pena de prisión de seis meses a dos años o multa de ocho a veinticuatro meses y, en todo caso, inhabilitación especial para profesión u oficio e inhabilitación especial para el ejercicio del derecho de cazar o pescar por tiempo de dos a cuatro años quien, contraviniendo las leyes u otras disposiciones de carácter general: a) cace, pesque, adquiera, posea o destruya especies protegidas de fauna silvestre; b) trafique con ellas, sus partes o derivados de las mismas; o, c) realice actividades que impidan o dificulten su reproducción o migración. La misma pena se impondrá a quien, contraviniendo las leyes u otras disposiciones de carácter general, destruya o altere gravemente su hábitat. 2. La pena se impondrá en su mitad superior si se trata de especies o subespecies catalogadas en peligro de extinción. 3. Si los hechos se hubieran cometido por imprudencia grave, se impondrá una pena de prisión de tres meses a un año o multa de cuatro a ocho meses y, en todo caso, inhabilitación especial para profesión u oficio e inhabilitación especial para el ejercicio del derecho de cazar o pescar por tiempo de tres meses a dos años".

28 Artículo 335 del Código Penal: "1. El que cace o pesque especies distintas de las indicadas en el artículo anterior, cuando esté 
el peligro que para la biodiversidad genera ${ }^{29}$, se castiga el uso de medios destructivos o no selectivos para la fauna sin autorización legal ${ }^{30}$.

Junto a estos tipos penales, el legislador castiga también los delitos de maltrato animal y de abandono de animales, que son los que van a centrar nuestro análisis.

Desde la tipificación del delito de maltrato animal en la reforma de 2003, se ha producido una evolución legislativa notablemente positiva y digna de resaltar para poder luchar de forma eficaz contra el maltrato y el abandono de los animales. Esta evolución ha tenido su culminación en la operada por la Ley Orgánica 1/2015, de 30 de marzo. Sin embargo no faltan autores ${ }^{31}$ que abogan por la necesidad compartida de seguir evolucionando con el objetivo de convertir al Código Penal en un instrumento útil para luchar de forma eficaz contra el maltrato y el abandono de los animales en España ${ }^{32}$.

Al hilo de esta cuestión, no faltan defensas que esgrimen el principio de intervención mínima del derecho penal para solicitar la absolución de los acusados, sobre la base de que el derecho penal debe tener carácter de última ratio por parte del Estado para la protección de los bienes jurídicos y solo para los más importantes frente a los ataques más graves. Al respecto, conviene recordar que la doctrina del Tribunal Supremo sobre "el principio de intervención mínima, o de «ultima ratio», va dirigido al legislador y no al aplicador de la norma, quien sólo cuando los términos del legislador no fueron claros, asume el principio como criterio de evaluación interpretativa, sabiendo el juez que la opción normativa del legislador hubo de ser la de menor expansividad de la norma penal" ${ }^{33}$. Y en cualquier caso, como ha señalado la jurisprudencia menor, "el principio de intervención mínima es incompatible con el enérgico juicio de reproche que en el momento actual merece el maltrato y abandono animal ante la imparable sensibilización y repulsa social frente a los mismos, con lo que se impone una política criminal de tolerancia cero" 34 .

\section{El delito leve de abandono de los animales}

\footnotetext{
expresamente prohibido por las normas específicas sobre su caza o pesca, será castigado con la pena de multa de ocho a doce meses e inhabilitación especial para el ejercicio del derecho de cazar o pescar por tiempo de dos a cinco años. 2. El que cace o pesque o realice actividades de marisqueo relevantes sobre especies distintas de las indicadas en el artículo anterior en terrenos públicos o privados ajenos, sometidos a régimen cinegético especial, sin el debido permiso de su titular o sometidos a concesión o autorización marisquera o acuícola sin el debido título administrativo habilitante, será castigado con la pena de multa de cuatro a ocho meses e inhabilitación especial para el ejercicio del derecho de cazar, pescar o realizar actividades de marisqueo por tiempo de uno a tres años, además de las penas que pudieran corresponderle, en su caso, por la comisión del delito previsto en el apartado 1 de este artículo. 3 . $\mathrm{Si}$ las conductas anteriores produjeran graves daños al patrimonio cinegético de un terreno sometido a régimen cinegético especial o a la sostenibilidad de los recursos en zonas de concesión o autorización marisquera o acuícola, se impondrá la pena de prisión de seis meses a dos años e inhabilitación especial para el ejercicio de los derechos de cazar, pescar, y realizar actividades de marisqueo por tiempo de dos a cinco años. 4. Se impondrá la pena en su mitad superior cuando las conductas tipificadas en este artículo se realicen en grupo de tres o más personas o utilizando artes o medios prohibidos legal o reglamentariamente".

${ }^{29}$ MUÑOZ CONDE (2015, p. 517)

${ }^{30}$ Artículo 336 del Código Penal: "El que, sin estar legalmente autorizado, emplee para la caza o pesca veneno, medios explosivos u otros instrumentos o artes de similar eficacia destructiva o no selectiva para la fauna, será castigado con la pena de prisión de cuatro meses a dos años o multa de ocho a veinticuatro meses y, en cualquier caso, la de inhabilitación especial para profesión u oficio e inhabilitación especial para el ejercicio del derecho a cazar o pescar por tiempo de uno a tres años. Si el daño causado fuera de notoria importancia, se impondrá la pena de prisión antes mencionada en su mitad superior

${ }^{31}$ En este sentido es interesante el trabajo realizado por BRAGE, S. ¿Es necesaria una nueva reforma penal en el ámbito de los delitos de maltrato y abandono de animales?, en Diario la Ley. 9187 (2018).

${ }^{32}$ Sin embargo, esta evolución debe venir acompañada de una debida formación en esta materia. MENÉNDEZ DEL LLANO, N. (2017) recuerda un dato preocupante cual es que si bien en los últimos dos años se han duplicado las denuncias por maltrato animal, sólo un 7\% de las causas penales de 2015 por estos delitos acabaron con una sentencia condenatoria. Y ello puede deberse a diversos factores como la falta de formación específica en Derecho Animal, la falta de sensibilidad entre los operadores jurídicos, que no siempre perciben los casos de maltrato animal como graves, o la falta de protocolos legales que determinen de oficio, por ejemplo, el decomiso del animal, el examen veterinario-forense del animal víctima del supuesto

${ }^{33}$ Sentencia de la Sala Segunda del Tribunal Supremo núm. 585/2017, de 20 de julio (ROJ STS 2969/2017) Ponente Excmo. Sr. D. Pablo Llarena Conde.

Disponible en: http://www.poderjudicial.es/search/AN/openDocument/2783a3a752d4953f/20170726 (consultado el 15 de julio de 2020).

${ }^{34}$ Sentencia de la Audiencia Provincial de Las Palmas de Gran Canaria, Sección 1. a, núm. 438/2019, de 30 de diciembre (ROJ SAP GC 1175/2019), que efectúa una interesante recopilación de los pronunciamientos judiciales habidos en materia de maltrato animal. Esta misma resolución añade más adelante una frase que demuestra una especial sensibilidad por parte de este Tribunal: "la Sala es plenamente consciente de la importancia de la protección de la vida e integridad de los animales y participa de un sano veganismo jurídico, pues a pesar de no tratarse de derechos constitucionalmente reconocidos, por el momento, su defensa forma parte, cada vez con mayor concienciación, de los valores propios de una sociedad democrática, solidaria e igualitaria, con lo que es creciente la sensibilización y repulsa social frente a los casos de maltrato animal, ante los que se impone una política criminal de tolerancia cero". Puede leerse esta resolución en http://www.poderjudicial.es/search/AN/openDocument/502fa9a0a6e4850d/20200331 (consultado el 28 de julio de 2020).
} 
El artículo 337 bis del Código Penal castiga al que abandone a un animal de los mencionados en artículo 337.1 en condiciones en que pueda peligrar su vida o integridad, con una pena de multa de uno a seis meses. Asimismo, el juez podrá imponer la pena de inhabilitación especial de tres meses a un año para el ejercicio de profesión, oficio o comercio que tenga relación con los animales, y para la tenencia de animales.

Se trata de un tipo penal incorporado por la Ley Orgánica 1/2015, de 30 de marzo, que sustituye al antiguo artículo 631.2 del Código Penal, que castigaba como falta con una pena de multa de quince días a dos meses a quienes abandonen a un animal doméstico en condiciones en que pueda peligrar su vida o su integridad. Por tanto, podemos considerar que el bien jurídico viene constituido por el respeto a la integridad física y psíquica del animal ${ }^{35}$.

La primera cuestión que nos planteamos es quién puede ser sujeto activo de este delito. El precepto no establece expresamente que el sujeto tenga que tener una especial condición, por lo que se puede afirmar que no solamente el propietario del animal podrá ser el autor. Ahora bien, a diferencia del delito de maltrato animal, en el cual el autor puede ser cualquier persona, lo que conocemos como un tercero, en el delito de abandono del art. 337 bis del Código Penal el dominio del hecho y la posibilidad de abandonarlo se circunscribirá a quien por uno u otro motivo esté en posesión y al cuidado del animal.

Siguiendo con la acción típica, si acudimos al Diccionario de la Real Academia de la Lengua, abandonar es "dejar solo algo o alguien alejándose de ello o dejando de cuidarlo". Se trata de un delito de peligro abstracto que no requiere de la producción de ningún resultado. Cuando hablamos de abandono, en primer lugar podemos pensar en desplazar o expulsar físicamente al animal fuera del entorno humano y posesorio en el que se encontraba, ámbito que posibilitaba la asistencia y cuidado a que viene obligado su propietario o poseedor, como podría ser dejarlo en el campo, en una carretera o en la vía pública, generando una situación de peligro para su vida o integridad.

Junto a esta conducta activa, es posible una conducta de abandono omisivo, que podríamos calificar como abandono funcional, ya sea por dejadez, desinterés o cualquier otro motivo. Decía Immanuel Kant que podemos juzgar el corazón de una persona por la forma en que trata a los animales ${ }^{36}$; pero lo cierto es que aquella conducta traspasa el plano ético y moral cuando el animal, aun estando bajo la esfera de nuestra posesión, sin que se hayan producido cambios en este sentido, no reciba la alimentación, cobijo y cuidado adecuado para procurar su bienestar, lo que también pueda poner en peligro la vida o integridad del animal.

Si acudimos a la teoría jurídica del delito, estaríamos ante un supuesto de comisión por omisión del artículo 11 del Código Penal, que dispone que "los delitos que consistan en la producción de un resultado sólo se entenderán cometidos por omisión cuando la no evitación del mismo, al infringir un especial deber jurídico del autor, equivalga, según el sentido del texto de la ley, a su causación. A tal efecto se equiparará la omisión a la acción: a) cuando exista una específica obligación legal o contractual de actuar; y b) cuando el omitente haya creado una ocasión de riesgo para el bien jurídicamente protegido mediante una acción u omisión precedente". Sin ningún género de duda, estos deberes más elementales de cuidado, de forma incuestionable, conciernen al propietario y titular de la explotación en la que se cría a los animales, a quien le corresponde por disposición legal o contractual una posición de garante de la vida y la salud del animal en los términos que determina el artículo 11 del Código Penal ${ }^{37}$.

El precepto establece una remisión a los animales previstos en el artículo 337.1 del Código Penal, esto es, “a) un animal doméstico o amansado; b) un animal de los que habitualmente están domesticado; c) un

\footnotetext{
${ }^{35}$ La cuestión relativa al bien jurídico es controvertida. VERCHER, A. (2017) considera que el bien jurídico protegido del delito de maltrato sería un derecho, o una modalidad de derecho, que ostentarían los propios animales. Por su parte, DURAN, I (2016) considera que a la vista de nuestra normativa procesal es difícil hablar de derechos propios de los animales. En su opinión, puede defenderse que el bien jurídico es un deber de los hombres hacia los animales y no como derechos propios de los animales, y el bienestar animal, entendido como la ausencia de sufrimientos innecesarios. La discusión ha traspasado el ámbito doctrinal y ha sido abordada por los Tribunales. En este sentido resulta interesante la reflexión realizada por la Sentencia de la Audiencia Provincial de Salamanca, Sección $1 .^{a}$ núm. 33/2020, de 23 de junio (ROJ SAP SA 412/2020), cuando dispone que "concurren varias posiciones (una que es la dignidad del animal como ser vivo, que debe prevalecer frente a quien desprecia la integridad física del animal, y la otra el bienestar animal). En algunos casos la jurisprudencia homogeniza las dos posiciones mencionadas, asimilando el bienestar animal a la atribución de derechos subjetivos, como es el caso de la Sentencia de la Audiencia Provincial de Cáceres (Sección 2a ), núm. 365/2018 de 5 de junio de 2018: "[...] el delito del art 337 CP , cuyo bien jurídico protegido es el animal doméstico o el bienestar animal, esto es, el derecho del animal a gozar de una vida, salud e integridad física y psíquica, sin sufrimientos innecesarios". Con la otra, los sentimientos que experimentan las personas hacia los animales, lo que se pretende proteger es la moral pública y las buenas costumbres de la sociedad, $\mathrm{o}$, en otras palabras, se aspira a prevenir futuras agresiones a humanos y en consecuencia, consideran que con la penalización del maltrato animal se persigue, indirectamente, la tutela de la sociedad, que es la verdadera titular del bien jurídico.)".

${ }^{36}$ Fuente consultada el 23 de julio de 2020: https://www.frasesypensamientos.com.ar/autor/immanuel-kant.html

37 Un ejemplo reciente lo encontramos en la Sentencia de la Audiencia Provincial de Asturias, Sección 3. a, de fecha 28 de febrero de 2020 (ROJ SAP O 686/2020), que confirmó la condena de la propietaria y poseedora de los animales que tenía en propiedad, al tener encerrados a los animales sin alimento y sin apenas agua durante días con altas temperaturas. Esta resolución puede examinarse en la página web http://www.poderjudicial.es/search/AN/openDocument/ed0b87058cd784d0/20200422 (consultada el 2 de agosto de 2020).
} 
animal que temporal o permanentemente vive bajo control humano, o d) cualquier animal que no viva en estado salvaje". Por consiguiente, el precepto no protege a todos los animales sino que restringe la tipicidad a cualquier tipo de animal que no viva en estado salvaje y que esté bajo el control humano. De esta manera se incluyen tanto el maltrato a los animales domésticos como también a los destinados al consumo humano, los animales exóticos, los animales de un zoo o de un circo.

Las víctimas de este delito son los animales. Sin duda, el Estatuto de la Víctima, aprobado por Ley $4 / 2015$, de 27 de abril, ha supuesto un gran avance al regular y unificar bajo una misma norma un conjunto de derechos procesales y extraprocesales de cualquier víctima de un delito; pero en consonancia con la normativa civil y procesal existente, el concepto de víctimas se circunscribe a las personas físicas. Todavía queda un largo camino por recorrer en el que los animales dejen de considerarse el mero objeto material derivado de la comisión de un delito.

Por último, es importante precisar que cuando este abandono se traduzca en un daño a la salud o la muerte del animal, los hechos serán constitutivos de un delito de maltrato animal del art. 337 del Código Penal, tipo penal que vamos a analizar a continuación.

\section{El delito de maltrato animal}

El Código Penal castiga el maltrato de los animales en su artículo 337, cuando dispone que "será castigado con la pena de tres meses y un día a un año de prisión e inhabilitación especial para el ejercicio de profesión, oficio o comercio que tenga relación con los animales y para la tenencia de animales, el que por cualquier medio o procedimiento maltrate injustificadamente, causándole lesiones que menoscaben gravemente su salud o sometiéndole a explotación sexual, a a) un animal doméstico o amansado; b) un animal de los que habitualmente están domesticado; c) un animal que temporal o permanentemente vive bajo control humano, o d) cualquier animal que no viva en estado salvaje" 38 .

El verbo utilizado por el legislador para describir la acción típica es el que sirve para definir el tipo penal: maltratar ${ }^{39}$. Si acudimos al Diccionario de la Real Academia de la Lengua, maltratar supone "causar daño físico o moral a una persona o un animal, generalmente con golpes o insultos" ${ }^{40}$. Ahora bien, ¿en qué consiste menoscabar gravemente su salud? Esta cuestión ha sido abordada recientemente y de forma extensa por la Sala de lo Penal del Tribunal Supremo en su Sentencia 186/2020, de 20 de mayo ${ }^{41}$. El Alto Tribunal señala que "lo más plausible es establecer un parangón con las figuras penales de similares perfiles, en este caso las que protegen la integridad física de los humanos: los delitos de lesiones. Esta parece ser la pauta seguida por el legislador a la vista de la similitud en el enunciado de las modalidades agravadas previstas en uno y otro caso". Y tras plantearse diversas posibilidades, la Sala concluye que " (...) será necesario que el animal requiera para su curación tratamiento veterinario, más allá del que se agota en una primera asistencia. Ahora bien, ese único presupuesto abarcaría detrimentos de la salud que difícilmente soportarían el calificativo de graves, lo que exige un plus que dependerá de las circunstancias del caso. Este podrá venir determinado por diversos factores. Entre ellos, sin afán de fijar un catálogo exhaustivo, habrán de valorarse la intensidad de la intervención veterinaria requerida; si hubiera exigido o no hospitalización; el riesgo vital generado por la herida o su potencialidad para acelerar significativamente procesos degenerativos; el periodo de tiempo durante el cual el animal haya estado imposibilitado para el desempeño de la actividad propia de su especie; y las secuelas o padecimientos permanentes. Sin olvidar que, si éstos últimos conllevan la pérdida de un sentido, órgano o miembro principal, necesariamente determinaran la imposición de la pena en su mitad superior (artículo 337.2)".

Como se puede observar, el legislador castiga el uso de cualquier medio o procedimiento. Este sistema de medios abiertos da cabida también a la omisión en consonancia con lo que hemos expuesto al analizar el delito de abandono. Por consiguiente, serán punibles tanto los golpes con las manos, patadas u objetos como los supuestos en los que no se alimenta al animal o no se le lleva al veterinario cuando tiene necesidad.

No obstante, no cualquier maltrato entra dentro de la esfera de protección del precepto. El legislador ha utilizado el término de maltrato "injustificado", término que no ha estado exento de una cierta controversia,

\footnotetext{
${ }^{38}$ BRAGE, S., en la obra ya citada, considera que es incomprensible la exclusión de los animales salvajes, y aboga por introducir la expresión animal vertebrado en la línea del derecho penal alemán.

${ }^{39}$ No está demás destacar que esta terminología constituye una diferencia con los tipos penales aplicables a las personas, dado que el artículo 147.1 del Código Penal habla de "causar a otro una lesión que menoscabe su integridad corporal o su salud física o mental"; y el apartado tercero habla de "golpear o maltratar de obra a otro sin causarle lesión".

${ }^{40}$ Como señala DELGADO, A (2011), el menoscabo a la salud comprende las conductas físicas, pero también las psicológicas.

${ }^{41}$ Sentencia de la Sala de lo Penal del Tribunal Supremo núm. 186/2020, de 20 de mayo (ROJ STS 1159/2020) Ponente Excma. Sra.

D. ${ }^{a}$ Ana María Ferrer García. La sentencia está disponible en

http://www.poderjudicial.es/search/AN/openDocument/d5a4b436348ed44b/20200602
} 
porque a priori ningún maltrato puede ser justificado, pero que busca excluir del tipo conductas que se encuentren legalmente permitidas y/o autorizadas, como es el caso de la experimentación con animales en laboratorios para la investigación ${ }^{42}$.

No estamos ante un delito de peligro sino ante un delito de resultado salvo la modalidad típica de explotación sexual, que sería mera actividad y se consumaría al realizar dicha conducta. El delito se consuma cuando el maltrato se concreta en la causación de una lesión que menoscabe gravemente la salud del animal o se produce su sometimiento a explotación sexual. En consonancia con lo que hemos expuesto en el delito de abandono de animales, la acción delictiva admite la comisión por omisión.

Aunque los elementos objetivos pueden ejecutarse en un solo acto, lo habitual es que sea el resultado de una conducta prolongada en el tiempo. Jurisprudencialmente se ha admitido la posibilidad de aplicar la continuidad delictiva del artículo 74 del Código Penal, que desde el punto de vista punitivo obligaría a imponer la pena en la mitad superior ${ }^{43}$.

Desde el punto de vista de los elementos subjetivos del tipo, se trata de un delito doloso. No está prevista la modalidad imprudente. Eso sí, será posible tanto el dolo directo como el dolo eventual.

El tipo básico está castigado con pena de hasta 1 año de prisión e inhabilitación para el ejercicio de profesión, oficio o comercio que tenga relación con los animales y para su tenencia de hasta 3 años. Salvo aquellos casos en los que la persona sea reincidente, el limite punitivo de un año habilitará para que la pena pueda ser suspendida de ordinario atendiendo a los artículos 80 y siguientes del Código Penal ${ }^{44}$. El apartado segundo prevé tipos cualificados cuando "se hubiere utilizado armas, instrumentos, objetos, medios, métodos o formas concretamente peligrosas para la vida del animal", "hubiera mediado ensañamiento", "se hubiera causado al animal la pérdida o la inutilidad de un sentido, órgano o miembro principal", o "los hechos se hubieran ejecutado en presencia de un menor de edad". En todos estos casos, se impondrá la pena en su mitad superior. Finalmente, cuando se produzca la muerte del animal, se establece un tipo cualificado castigado con penas de hasta 18 meses de prisión e inhabilitación especial de 2 a 4 años para el ejercicio de profesión, oficio o comercio que tenga relación con los animales y para la tenencia de animales ${ }^{45}$.

Cuando el maltrato no consista en someter a explotación sexual al animal, cuando no le cause lesiones o cuando causando lesiones no menoscaben gravemente su salud, los hechos podrán ser constitutivos de un delito leve de maltrato tipificado en el cuarto y último apartado del artículo 337 del Código Penal. Este precepto dispone que "los que, fuera de los supuestos a que se refieren los apartados anteriores de este artículo, maltrataren cruelmente a los animales domésticos o cualesquiera otros en espectáculos no autorizados legalmente, serán castigados con una pena de multa de uno a seis meses". Con carácter potestativo, el juez podrá imponer la pena de inhabilitación especial de 3 meses a 1 año para el ejercicio de profesión, oficio o comercio que tenga relación con los animales y para la tenencia de animales. La interpretación de este delito leve fue objeto de análisis también en la sentencia del Tribunal Supremo de 20 de mayo de 2020 a la que anteriormente hemos aludido. La Sala de lo Penal ha considerado que "el tipo penal no requiere el tipo la habitualidad, pero el adverbio modal "cruelmente" añade una nota de dureza o perversidad, de gratuidad en la actuación que permita deducir una cierta complacencia con el sufrimiento provocado. Presupuesto que podrá cumplirse, bien con un proceder aislado de suficiente potencia, o con una reiteración de actos que precisamente por su persistencia en el tiempo impliquen un especial desprecio hacia el sufrimiento y dolor susceptibles de irrogar”. Igualmente, el Tribunal Supremo solventa la discusión existente en la jurisprudencia menor sobre el alcance del objeto del delito y concluye que el maltrato cruel de los animales domésticos es punible se realice o no en espectáculos autorizados legalmente ${ }^{46}$.

\section{Conclusiones}

1. Para paliar los efectos devastadores del Covid-19, el gobierno se ha visto obligado a confinar durante varios meses a la población, restringiendo su libertad de circulación, así como adoptar otras medidas

\footnotetext{
${ }^{42}$ La reforma operada por la Ley Orgánica 5/2010, de 22 de junio eliminó el requisito del ensañamiento. Como recogió el preámbulo de la propia reforma, este requisito dificultaba de manera notable de la aplicación del precepto. Puede examinarse esta reforma en https://www.boe.es/diario_boe/txt.php?id=BOE-A-2010-9953 (consultado el 23 de julio de 2020).

${ }^{43}$ El artículo 74.1 del Código Penal dispone: "No obstante lo dispuesto en el artículo anterior, el que, en ejecución de un plan preconcebido o aprovechando idéntica ocasión, realice una pluralidad de acciones u omisiones que ofendan a uno o varios sujetos e infrinjan el mismo precepto penal o preceptos de igual o semejante naturaleza, será castigado como autor de un delito o falta continuados con la pena señalada para la infracción más grave, que se impondrá en su mitad superior, pudiendo llegar hasta la mitad inferior de la pena superior en grado".

${ }^{44}$ Como señala MAGRO, V. (2016) es importante que esta suspensión se condicione a participar en programas de protección de los

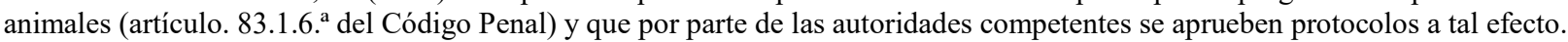

${ }^{45}$ La reforma de 2015 introduce estos subtipos agravados y da un tratamiento punitivo individualizado al resultado de muerte, evitando la situación preexistente en la que el marco penal por menoscabar la salud del animal y por ocasionarle la muerte era el mismo.

${ }^{46}$ Vid. nota al pie núm. 41.
} 
con graves repercusiones económicas; y para ello se ha recurrido a la figura del estado de alarma, lo que ha generado un arduo debate doctrinal sobre la legalidad de las medidas adoptadas.

2. El abandono normativo de los animales se ha visto acentuado durante esta época. Basta examinar el Real Decreto por el que se declaró el estado de alarma para llegar a esta conclusión: no existe prácticamente ninguna mención más allá de la no suspensión de la actividad de apertura al público de los establecimientos comerciales minoristas de alimentos para animales de compañía. Pero es más, la debilidad de estos seres sintientes se ha visto agravada al ser instrumentalizados por algunos ciudadanos, que han visto en los animales una vía para burlar las medidas de confinamiento.

3. En el campo del derecho civil, la pandemia ha puesto de manifiesto nuevamente la necesidad de que se produzca la descosificación de los animales y un adecuado régimen jurídico desligado de las cosas muebles, por ejemplo en materia de familia. Es más, resultaría deseable un reconocimiento expreso al bienestar animal en nuestra Constitución.

4. En el campo del derecho penal, los abandonos de animales que puedan producirse como consecuencia de aquella instrumentalización tendrán una debida respuesta en el Código Penal. Ello es gracias a la evolución habida desde el año 2003, que no puede calificarse más que de positiva. La introducción de los tipos penales de abandono y maltrato animal han supuesto un gran avance, pero todavía queda un largo camino por recorrer: la necesidad de proteger a todo tipo de animales, salvajes o no, una adecuada respuesta punitiva, proporcionada a la gravedad de los hechos, una necesaria formación y especialización por parte de los operadores jurídicos $\mathrm{y}$, sobre todo, una constante campaña de sensibilización por parte de los poderes públicos se antojan indispensables a tal fin.

\section{Bibliografía}

- BRAGE, S. ¿Es necesaria una nueva reforma penal en el ámbito de los delitos de maltrato y abandono de animales?, en Diario la Ley. 9187 (2018).

- DELGADO, A. Algunas supresiones, transformaciones y ciertos añadidos en el delito de maltrato a animales domésticos (y amansados) del art. 337 CP tras la reforma de la Ley Orgánica 5/2010, en la Ley Penal: revista de Derecho penal, procesal y penitenciario. 79 (2011) 33-36.

- DURÁN, I. El maltrato y el abandono de animales desde el punto de vista del derecho penal (LO 1/2015, de 30 de marzo), en la Ley Penal: revista de Derecho penal, procesal y penitenciario. 123 (2016).

- GIMÉNEZ-CANDELA, T. La descosificación de los animales (I), en Revista de derecho animal. Vol. 8 núm. 2 (2017).

- HENAO, S. Eutanasia en animales de compañía, dilemas, encuentros y desencuentros, en Revista Colombiana de Bioética, vol. 11 n. 3 (2017). Página web: https:Ildoi.org/10.18270/rcb.v11i3.2163

- JIMÉNEZ, F. Delitos relativos a la protección de la flora y la fauna: tipos penales en blanco y relación con el derecho administrativo sancionador, en Encuentro entre fiscales y jueces en el foro medioambiental. Cuadernos digitales de formación, Madrid: Consejo General del Poder Judicial, 42009 (2010).

- MAGRO, V. El delito de maltrato animal en el Código Penal tras la L.O. 1/2015 y la reeducación de los condenados, en Diario la Ley. 8841 (2016).

- MENÉNDEZ DEL LLANO, N. Evolución de la sanción penal por maltrato animal: el caso español, en Diario la Ley. 9038 (2017).

- MUÑOZ, F. Derecho Penal Parte Especial, Valencia: Editorial Tirant lo Blanch, ed. 20. (2015), pp. 511 y ss.

- VERCHER, A. Nuevas perspectivas sobre el bien jurídico protegido en los delitos ambientales: ¿cabría hablar de derechos no humanos de los animales domésticos frente a su maltrato?, en Diario la Ley. 8894 (2017). 